\title{
Distribuição da calda na cultura da videira por turboatomizador com diferentes configurações de pontas
}

\author{
Grapevine spray distribution by an air-assisted sprayer with different nozzles configuration
}

\author{
Marcelo Gonçalves Balan ${ }^{1}$ Otavio Jorge Grigoli Abi Saab ${ }^{2}$ Enio Hyroyuki Sasaki ${ }^{3}$
}

\section{RESUMO}

As variedades de uva fina de mesa são susceptíveis a doenças. Em virtude disso o controle é responsável pela maior parte do custo de produção. Visando a diminuir os desperdícios, a contaminação e a criação de resistência, a tecnologia de aplicação de agrotóxicos é de suma importância neste processo. Este trabalho teve como objetivos avaliar a configuração de bicos e pontas de pulverização utilizada e propor outras mais adequadas à aplicação de agrotóxicos com turboatomizador em videira. Utilizou-se papel sensível à água para avaliar a cobertura em 16 pontos de amostragem da parreira. Foram observados pontos de acúmulo e de deficiência de cobertura da calda de pulverização. Com modificações na abertura e/ou fechamento dos bicos na barra de pulverização, com a utilização de pontas de pulverização do tipo jato plano ou com a mistura de pontas do tipo jato cônico vazio de diferentes vazões foi possível obter configurações mais adequadas para aplicação de agrotóxicos em videira com taxas de aplicação entre 250 a $400 \mathrm{~L} \mathrm{ha}^{-1}$.

Palavras-chave: assistência de ar, cobertura, pontas de pulverização.

\section{ABSTRACT}

Fine grape varieties are susceptible to a large number of diseases and its control is responsible for the largest production expenses. The agrochemical technology application has great addition importance in this process, to reduce the waste, contamination and resistance. This research had as objectives to evaluate the commonly nozzles configuration used and to propose other more appropriate to the application of agrochemicals with air assisted sprayer. Water sensitive papers were used to evaluate the coverage on 16 vineyard sampling points. Accumulation points and deficiency of spray coverage can be observed. It was possible to get more appropriate configuration opening or closing the spray boom nozzles, using flat fan nozzles or the mixture of hollow cone with different flow rates, for grapevine pesticide application taxes among 250 to

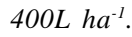

Key words: air assistance, coverage, nozzles.

\section{INTRODUÇÃO}

Por estar sujeita à incidência de várias doenças, o cultivo de variedades de uva fina, principalmente a cultivar Itália e suas mutações somáticas, apresenta, no montante de intervenções de controle químico, o qual pode chegar a até 50 aplicações por ciclo da cultura, o maior gasto em termos monetários.

As recomendações de agrotóxicos para a videira são, via de regra, baseados na concentração do produto com relação ao volume de calda a ser aplicado. Os produtores, buscando melhorar sua eficiência (rendimento operacional) e reduzir seus custos com agrotóxicos, têm utilizado tecnologias de aplicação alternativas, como o uso de pulverizador hidráulico com fluxo de ar (turboatomizador), visando sempre ao menor volume de calda a ser aplicado.

O fluxo de ar gerado no turboatomizador tem como objetivo favorecer a trajetória das gotas pulverizadas em direção ao alvo, interferindo em sua penetração e conseqüente deposição. A velocidade, a trajetória e o fluxo de ar proporcionado por turboatomizadores, como também seus efeitos,

${ }^{1}$ Programa de Pós-graduação em Agronomia, Universidade Estadual de Londrina (UEL), Rua Irati, 66, 86060-540, Londrina, PR, Brasil. E-mail: balan@uel.br. Autor para correspondência.

${ }^{2}$ Departamento de Agronomia, Centro de Ciências Agrárias, UEL, Londrina, PR, Brasil.

${ }^{3}$ Curso de Agronomia, UEL, Londrina, PR, Brasil. 
precisam ser mais bem estudados e relacionados com os estádios da cultura e ainda com os volumes aplicados e tamanhos de gotas geradas por ocasião da configuração de pontas na barra de pulverização. O desperdício na aplicação e o uso de mesmo princípio ativo para o controle de determinadas doenças são dois dos maiores problemas encontrados hoje na cultura da videira.

Apesar da grande importância no sistema de produção, os agrotóxicos têm sido alvo de grande preocupação social, principalmente no que concerne a seu potencial de risco ao ambiente (BARCELLOS et al., 1998).

A pulverização é um processo mecânico de geração de um grande número de pequenas partículas (gotas) de uma calda (mistura, suspensão ou diluição), e a aplicação é o processo de se colocar o produto químico pulverizado no alvo (CHRISTOFOLETTI, 1999).

O uso da pulverização, com a finalidade de controle fitossanitário, depende não somente de produtos de ação comprovada, mas também da tecnologia desenvolvida para sua aplicação. A pulverização fica ainda condicionada ao momento de sua realização e à influência dos fatores meteorológicos e biológicos. A eficiência da pulverização é afetada pela forma, tamanho e posição do alvo, pela densidade, diâmetro e velocidade de gota e pela velocidade e direção do fluxo de ar.

Os fatores que influenciam as características da deriva, conforme SATOW et al. (1993), são, além do tamanho das gotas, a velocidade, a turbulência e a direção do vento. $\mathrm{O}$ volume de aplicação, a distância do alvo, a pressão, a velocidade e a energia cinética das partículas pulverizadas também influenciam diretamente a deriva.

Quanto maior a intensidade dos ventos e menores as gotas produzidas, maior será a quantidade de gotas desviadas. Como a água é o agente de diluição da maioria dos produtos comercializados, a evaporação tem papel importante numa aplicação. Para que as gotas “desapareçam” deve haver a contribuição do tamanho da gota, da umidade relativa do ar e da temperatura. A cobertura está relacionada com a função do produto utilizado (modo de ação) e com o alvo (tamanho, forma, exposição, capacidade de retenção) que se pretende atingir (CHRISTOFOLETTI, 1999).

Os diâmetros das gotas formadas são diferentes nos diversos equipamentos para pulverização, apesar da alta tecnologia empregada. $\mathrm{O}$ ideal é que se consiga uma maior homogeneidade no tamanho das gotas, sendo que o bico de pulverização é o elemento que mais influencia na qualidade do tratamento desejado (BLANCA, 1999).

Sobre tamanho de gota, pode-se afirmar que a técnica de uso de agrotóxicos está em produzir uma pulverização com gotas que sejam suficientemente grandes para não se perderem por evaporação e deriva, mas que sejam pequenas o bastante para produzir uma boa cobertura do alvo. ABI SAAB (1996) destaca que gotas menores não necessariamente promoverão melhores coberturas e deposições. Isso depende, dentre outros fatores, do efeito do vento e da orientação do bico. A importância do tamanho das gotas cresce em função do aumento da dificuldade de alcance do alvo(STEDEN, 1992).

A pulverização consiste na aplicação de produto com gotas de diâmetro superior a 150 micras (SILVEIRA, 2001). Na atomização, as partículas têm diâmetro entre 50 e 150 micras. Nos turboatomizadores, os bicos estão localizados ao redor de uma turbina com saída periférica de ar. Esta constituição melhora a eficiência da máquina, uma vez que o ar expelido pela turbina desloca a atmosfera inerte, localizada no interior da planta, facilitando a penetração das gotículas. Apesar da aplicação de agrotóxicos ser uma prática comum entre os agricultores, algumas noções básicas sobre a eficiência desses tratamentos ainda são desconhecidas pela maioria dos técnicos, dos produtores e dos trabalhadores rurais. Isso tem levado a consideráveis desperdícios de produtos, de máquinas e de mão-deobra. A utilização de turboatomizadores constitui-se num excelente exemplo de como a adequação e a correta utilização de pulverizadores pode interferir de forma significativa no custo de produção (RAMOS, 2004).

Os conceitos empregados, na época em que os pulverizadores de pistola eram os mais utilizados nos tratamentos fitossanitários, têm sido repassados aos atuais turboatomizadores, gerando perdas acentuadas, comprometendo a eficácia do sistema e levando à utilização de volumes de calda cada vez maiores.

A importância técnica e econômica relacionada à melhoria da segurança e efetividade nos métodos de aplicação de agrotóxicos em videiras e outras frutíferas são evidenciados por GIL et al. (1998). Esses autores conferem à seleção correta de tecnologia uma importância fundamental no resultado final das aplicações de agrotóxicos, pois o objetivo da mesma não é uma superfície, mas sim um volume de vegetação. Ações fáceis e rápidas, como calibração precisa dos recursos do pulverizador, logo antes da aplicação, 
permitem reduzir em $50 \%$ o volume aplicado, mantendo a sua eficácia (GIL et al., 1998).

Melhorias na uniformidade da distribuição da calda aplicada são cada vez mais importantes, e um grande controle da aplicação é necessário para permitir uma ótima distribuição do produto sobre o alvo. Esses fatores são particularmente importantes nos cultivos de frutíferas, nos quais a heterogeneidade do alvo dificulta uma aplicação uniforme nas diferentes partes das plantas (GIL et al., 1996). Os pulverizadores hidráulicos com fluxo de ar são os mais utilizados em frutíferas (HOLOWNICKI et al., 2000). De acordo com esses autores, esses equipamentos não são caros, são fáceis de operar e efetivos em controle de pragas e doenças. Entretanto, a pulverização em frutíferas é considerada como um processo pouco eficiente, porque mais da metade da dose do agrotóxico é perdida. Uma parte significativa das pulverizações em pomares, quando se utiliza turboatomizadores, não é depositada no alvo, mas sim perdida no ar e no solo, implicando perdas econômicas e poluição ambiental. É indispensável o uso de assistência de ar para que se vença a distância entre o pulverizador e o alvo pretendido, sendo que o volume de ar deve ser ajustado, às circunstâncias específicas de aplicação, visando a reduzir essas perdas (KAUL et al., 2002).

A intensidade do fluxo do ar nos turboatomizadores é determinada pela velocidade de ar gerada pela turbina, influenciando diretamente a distribuição vertical do líquido aplicado. Com volume e velocidade do ar baixos, produzido pela turbina, o produto aplicado alcançará o objetivo insuficientemente. Com velocidade muito alta do ar, o produto é soprado através e acima do alvo (VEREECKE et al., 2000). Diferentes projetos e características de difusores têm sido desenvolvidos para pulverizadores com fluxo de ar (GIL, 2000) e apresentados no mercado. Em relação à turbina, RAMOS (2004) descreve que a sua altura tem interferência sobre a eficácia em relação à planta. Turbinas baixas fazem com que as últimas pontas de pulverização (de ambos os lados extremos da barra) fiquem muito longe do alvo, resultando em sérias implicações para a planta. Esse autor afirma que quanto maior for a distância entre as pontas de pulverização e o alvo, menor será a capacidade do ar em transportar as gotas e maior será a probabilidade de evaporação e deriva.

O uso apropriado de assistência de ar é exigido para melhorar a distribuição de depósitos e a eficiência de coleta dos produtos fitossanitários aplicados pelas diversas partes da planta (MATTHEWS, 2000). Em larga escala, a partição da pulverização dentro da cultura é afetada pela taxa de corrente de ar (PERGHER et al., 1995), pela sua velocidade aerodinâmica (RANDALL, 1971), como também pela orientação da corrente de ar e pelo número de saídas usadas para direcionar o ar e a calda pulverizada para a cultura (FURNESS \& PINCZEWSKI, 1985; GOHLICH, 1985; PERGHER et al., 1997; PEZZI \& RONDELLI, 2000). Para uma mesma quantia de potência dispensada, uma taxa de fluxo de ar mais alta a uma baixa velocidade aerodinâmica propiciou uma melhor penetração da calda e produziu uma cobertura de folha melhor do que baixos volumes de ar com velocidade mais alta (RANDALL, 1971). Essa constatação é verdadeira, contanto que a velocidade aerodinâmica do ar seja alta o bastante para formar aberturas para a corrente de ar penetrar. A presença de mais ar não implica automaticamente uma cobertura melhor. O depósito de calda total foi melhor quando estava se usando uma baixa taxa de fluxo de ar, enquanto que, para uma taxa maior, foi aumentada a quantia de gotas atomizadas sopradas através da cultura (HOLOWNICKI et al., 2002). Estes resultados foram reproduzidos quando a velocidade do vento era baixa. Mas, em velocidades mais altas, os depósitos eram mais baixos nas taxas menores (CROSS et al., 2003).

Os métodos utilizados para avaliar as aplicações exigem condições encontradas apenas em laboratórios. O desenvolvimento de métodos mais simples e confiáveis é um desafio antigo. Os papéis sensíveis a líquidos são muito utilizados como alvos artificiais, devido a facilidade de visualização, proporcionando interpretações imediatas. A determinação da distribuição das gotas e a cobertura do alvo podem ser realizadas através da utilização desses alvos artificiais, colocados próximos aos alvos verdadeiros, como folhas de plantas ou solo (NOGUEIRA, 1996). Essas análises visuais, com a utilização de papel sensível à água, embora não sejam consideradas as mais adequadas, são de grande valia para as observações imediatas, pois facilitam e podem nortear as modificações e/ou intervenções no sistema de aplicação.

Este trabalho teve como objetivos avaliar a condição de aplicação usual do produtor e propor configurações da distribuição de pontas de pulverização em turboatomizadores para aplicação de agrotóxicos em videiras, visando a uma maior eficiência e a melhores rendimentos operacionais, assim como a uma menor contaminação do operador e do ambiente.

\section{MATERIAL E MÉTODOS}

O trabalho foi realizado em uma propriedade localizada no município de Marialva, Estado do Paraná, 
com altitude aproximada de 600m (2325'32,6”s e 514ㅇ'42,1"WO). Utilizou-se uma parreira da variedade Rubi, com aproximadamente cinco anos de idade, implantada em espaçamento de 3 metros entre linhas e 6 metros entre plantas desencontradas, com altura média de 1,75 metro, produzindo através de estruturas condutoras permanentes do tipo caramanchão. Esse sistema permite maior expansão vegetativa das plantas e é mais utilizado para uvas finas de mesa no Estado do Paraná. Partindo-se da condição usual de um turboatomizador utilizado pelo produtor para aplicação de agrotóxicos em videiras, avaliou-se a distribuição do vento e das gotas em diferentes pontos da parreira. A partir da configuração inicial, promoveu-se alteração nas configurações, abrindo ou fechando os bicos até atingir uma situação considerada aceitável para aquelas condições.

Utilizou-se um conjunto de pulverização tratorizado composto de trator Yanmara 104-DT 4x4-H e pulverizador turboatomizador marca $\mathrm{KO}^{\mathbf{b}} \mathrm{A}-500$, com barra de pulverização para 14 bicos com posição (ângulo) regulável. As pontas de pulverização utilizadas foram: JA-1, JA-2 (jato cônico vazio) e 110LD-015 (jato plano), ambas da marca Jactoc. Também empregou-se água, papel sensível à água, trena, arame liso, cartolina, filme plástico, canetas, termohigroanemômetro, fita adesiva dupla face, luvas de borracha e trena.

Devido ao elevado custo, os papéis sensíveis foram confeccionados em laboratório através da imersão e posterior secagem de tiras de papel sulfite, com dimensões de $3 \mathrm{~cm}$ x $8 \mathrm{~cm}$, em solução composta de $1 \mathrm{~g}$ de azul de bromofenol diluído em $180 \mathrm{~mL}$ de tolueno e $20 \mathrm{~mL}$ de acetona.

Um arame liso foi fixado na parte interna do parreiral (rua), em uma área desfolhada, considerando a estrutura de condução da videira (Figura 1). Foram definidos 16 pontos de amostragens, sendo dez na estrutura de arame que suporta a massa de folhas e seis nas laterais, visando a avaliar também a distribuição lateral de agrotóxicos. Em cada ponto de amostragem, foram utilizadas placas de cartolina $(10 \mathrm{~cm}$ x $20 \mathrm{~cm})$ como suporte para seis papéis sensíveis à água, de 3 x 8cm cada. As placas foram então fixadas no arame disposto na estrutura de condução da cultura com fita dupla face. Os alvos foram dispostos na horizontal com distância de $0,50 \mathrm{~m}$ e duas posições de alvos na vertical com número de três alvos $(11 ; 12 ; 13)$ e $(14 ; 15 ; 16)$. A distância vertical partindo da horizontal para os alvos subsequentes (13; 12 e 14; 15) foi de 0,25m. A distância entre os alvos dispostos na vertical (11 - 12 e 15 - 16) foi de $0,50 \mathrm{~m}$ (Figura 1A).
Com o auxílio do anemômetro, obteve-se as médias da velocidade do vento gerado $\left(\mathrm{km} \mathrm{h}^{-1}\right)$ exclusivamente pelo turboatomizador em cada ponto de amostragem (posição dos alvos), definindo-se a classificação desses pontos após nove aferições para cada ponto, em três níveis, sendo: fraco - nas posições dos alvos 1, 2, 9, 10, 11, 12, 13, 16 (velocidades $<5 \mathrm{~km} \mathrm{~h}^{-1}$ ), bom - nas posições dos alvos 5, 6, 7, 8, 14, 15 (velocidades de 5,0 a $20 \mathrm{~km} \mathrm{~h}^{-1}$ ) e forte - nas posições dos alvos 3 e 4 (velocidades maiores que $20 \mathrm{~km} \mathrm{~h}^{-1}$ ) (Figura 1B).

Foram realizadas nove aplicações em 16 pontos de amostragem, com seis repetições em cada ponto, totalizando 864 amostras. A pressão de trabalho utilizada foi de $1.407 \mathrm{kPa}$ para os bicos cone e $227 \mathrm{kPa}$ para os bicos leque. Para cada aplicação, partindo-se da configuração original do turboatomizador (14 bicos com pontas do tipo JA-1), foram feitas avaliações visuais da cobertura propiciada aos papéis sensíveis (alvos artificiais). Após aproximadamente três minutos de cada aplicação, tempo suficiente para a secagem dos alvos artificiais, estes foram retirados e imediatamente embalados em filme de PVC para se evitar contaminação e o efeito não desejável de umidade. A realização dos tratamentos ocorreram nos seguintes horários e condições ambientais: figura $2 \mathrm{~A}$ - realizado às $10 \mathrm{~h} 30 \mathrm{~min}$, temperatura de $25,3^{\circ} \mathrm{C}, 52 \%$ de umidade relativa do ar e $3,6 \mathrm{~km} \mathrm{~h}^{-1}$ de velocidade média do vento; figura $2 \mathrm{~B}$ - realizado às $10 \mathrm{~h} 45 \mathrm{~min}$, temperatura de $24,3^{\circ} \mathrm{C}, 49 \%$ de umidade relativa do ar e $1,4 \mathrm{~km} \mathrm{~h}^{-1} \mathrm{de}$ velocidade média do vento.

Para as interpretações de cada amostra, a cobertura dos alvos foi avaliada em duas repetições, por dois avaliadores diferentes (duplo cego), sendo adotada a média das leituras, conforme VIEIRA \& HOFFMANN (1989), visando à atenuar a subjetividade. Para facilitar e proporcionar maior precisão a esta estimativa, elaborou-se uma escala de notas e adotouse um padrão de cobertura considerado satisfatório (10) e para cada amostra, comparativamente ao padrão, foi atribuído um valor da cobertura proporcionada pela calda de aplicação que variou em notas de 0 a 10, sendo admitidas notas fracionadas $(0,5)$. Após o cálculo das médias, as notas, em relação à cobertura propiciada aos alvos artificiais, foram assim classificadas: fraco (menor que 5,0), regular (entre 5,0 e 7,5) e bom (entre 7,5 e 10,0).

Ciência Rural, v.36, n.3, mai-jun, 2006. 


\section{RESULTADOS E DISCUSSÃO}

Já durante as primeiras avaliações na execução do trabalho, percebeu-se que houve uma variação muito grande da velocidade do vento emitido pelo turboatomizador nos diferentes pontos da parreira. Isso foi causado provavelmente pelo desenho da voluta e por obstáculos colocados à frente da saída de ar do equipamento, como a barra dos bicos, as mangueiras e suportes, gerando turbulência, um dos fatores apontados por SATOW et al. (1993) como responsáveis pela deriva da calda aplicada.

Pela simples observação visual do desenho da saída de ar do turboatomizador tem-se a falsa impressão de que há uma uniformidade da distribuição da saída de ar (Figura 1C).

No entanto, devido ao sentido da rotação da turbina do turboatomizador, o movimento do ar sofre um desvio lateral à direita, como visto na figura 1D. Esse fato provoca um maior direcionamento da calda de pulverização para o lado direito da parreira, considerando o sentido de deslocamento, facilmente percebido visualmente na figura $1 \mathrm{E}$.

Em todas as aplicações, pode-se perceber claramente dois pontos com excesso de calda: um no primeiro terço, à esquerda da entrelinha da parreira, considerando-se o sentido de deslocamento, ocasionado por obstáculos à frente da saída de ar; e outro à direita da entrelinha da parreira, ocasionado pela sentido da rotação da turbina.

Após testes, a solução encontrada para melhorar a distribuição da calda pulverizada foi fechar o quinto bico da esquerda para a direita, considerando o sentido de deslocamento, e os dois últimos bicos à direita. Com essa configuração, foi possível obter uma distribuição da calda considerada aceitável para esse tipo de equipamento. Também se pode considerar que houve uma economia aproximada de $20 \%$ de calda devido ao fechamento de três bicos, e que não houve áreas da entrelinha da parreira com excesso nem com falta do produto aplicado. Esse resultado confirma a afirmação de GIL et al., (1998), de que ações simples (como a precisa calibração do pulverizador antes da aplicação) podem reduzir o volume aplicado, porém mantendo a eficácia. Cabe ressaltar que essa configuração foi considerada adequada para pontas de jato plano (leque) 110-LD-015 (Figura 2A).

Já para o caso de aplicação com pontas de jato cônico vazio (JA-1), percebeu-se que a mesma configuração não promoveu cobertura adequada nas extremidades da entrelinha da parreira. A solução encontrada foi manter os mesmos bicos fechados, substituindo as pontas das extremidades por outras de maior vazão (JA-2). De acordo com ABISAAB (1996), a justificativa está no fato de que essas pontas produzem gotas de maior diâmetro e, conseqüentemente, maior massa e tempo de vida, tendo maiores possibilidades, com fluxo de ar adequado, de serem transportadas e depositadas no alvo. Assim a economia de calda ficou reduzida a pouco mais de $6 \%$, pois as pontas JA-2 têm o dobro de vazão da ponta JA-1 na pressão de trabalho utilizada no experimento.

No entanto, cabe ressaltar que o maior ganho está na qualidade da aplicação devido à distribuição mais uniforme, conforme MATTHEWS (2000), que afirma a exigência do uso apropriado da assistência de ar na melhor distribuição dos depósitos de calda. A figura 2B apresenta a configuração de bicos proposta para a utilização de pontas de jato cônico vazio.

Para o caso de espaçamento entrelinhas da parreira menor, 2,5m, por exemplo, pode-se optar por fechar mais um bico em cada extremidade da barra portabicos do equipamento. Entretanto, devido à turbulência, manteve-se fechado o quinto bico da esquerda para a direita considerando-se o sentido de deslocamento, como também as pontas de jato cônico de maior vazão nas extremidades da nova configuração a ser utilizada.

Para as configurações apresentadas e para o modelo de turboatomizador testado, pode-se trabalhar com volumes reduzidos de aplicação, entre 250 a 400L $\mathrm{ha}^{-1}$, em vez de volumes maiores de até $1.000 \mathrm{~L} \mathrm{ha}^{-1}$, geralmente utilizados pelos produtores na aplicação de fungicidas em videira.

\section{CONCLUSÕES}

A configuração original da distribuição das pontas de pulverização na barra de turboatomizadores nem sempre é a mais indicada para aplicações de agrotóxicos em videira. Com a abertura de alguns bicos e o fechamento de outros e com a utilização de pontas de pulverização do tipo jato plano ou com a mistura de pontas do tipo jato cônico vazio de diferentes vazões, é possível estabelecer uma distribuição de gotas e fluxo de ar que torne a aplicação mais uniforme, dependendo das condições encontradas em cada propriedade.

$\mathrm{O}$ método utilizado mostrou-se potencialmente apropriado, possibilitando redução do volume de calda aplicada por evitar a sobreposição. Deve, no entanto, ser adaptado e testado para ser utilizado em diferentes tipos de pulverizadores hidráulicos com fluxo de ar, volumes de calda, forma de condução e estádio fenológico da cultura. 


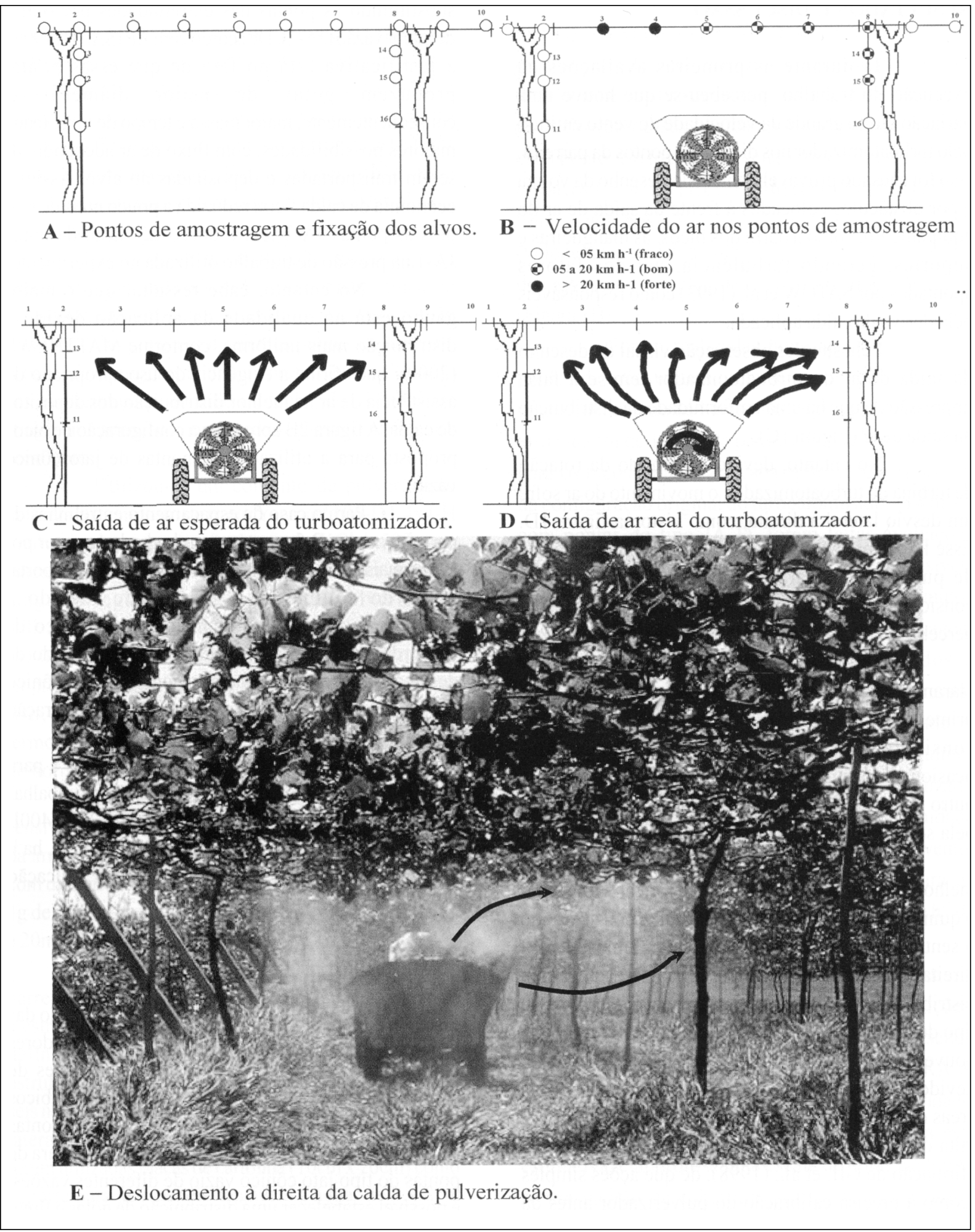

Figura 1 - Distribuição de alvos artificiais para avaliação da cobertura, aferição da velocidade do fluxo de ar, observação da saída do fluxo de ar e comportamento da distribuição da calda de pulverização por turboatomizador na cultura da videira. 


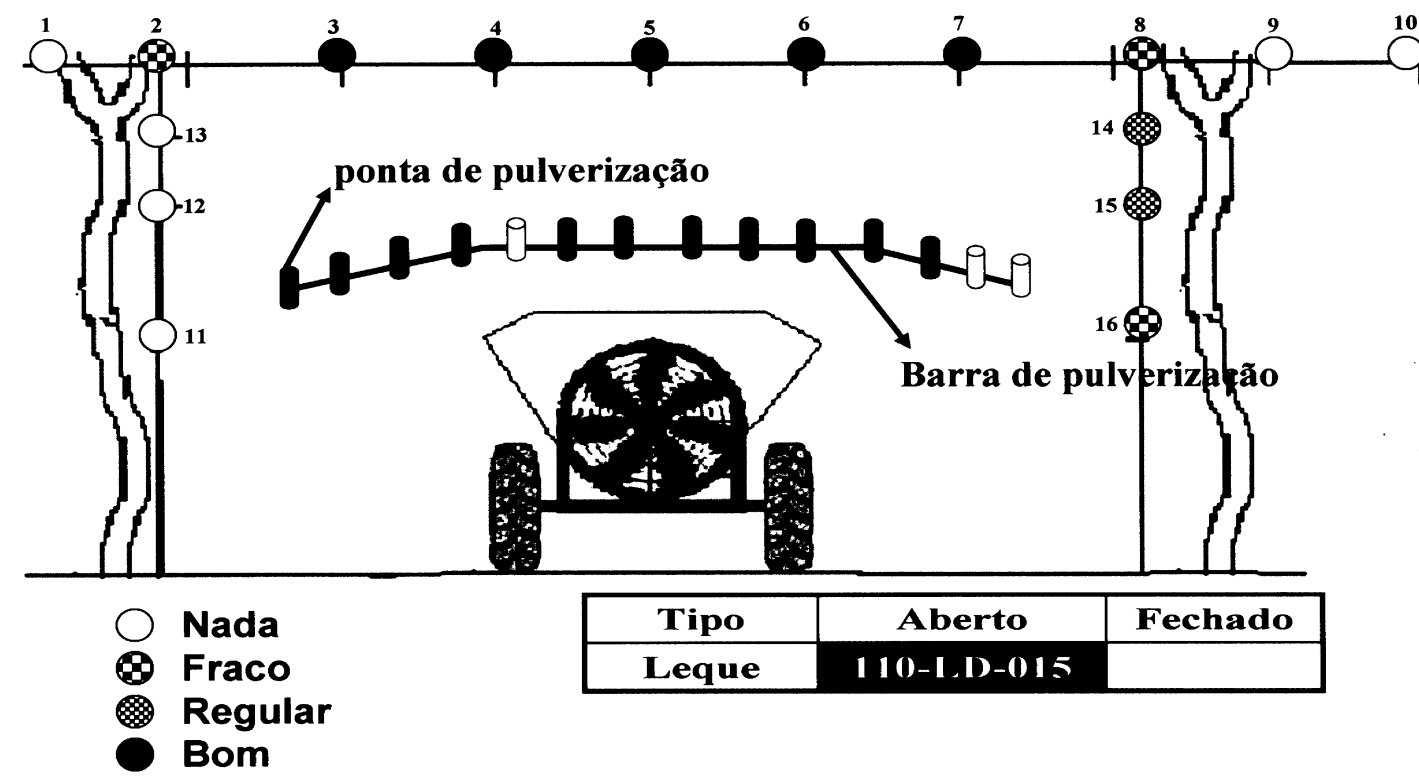

A - Configuração de pontas de pulverização considerada adequada para aplicação de agrotóxicos na videira com pontas de jato plano (leque) 110-LD-015, e as respectivas coberturas dos pontos de amostragem.

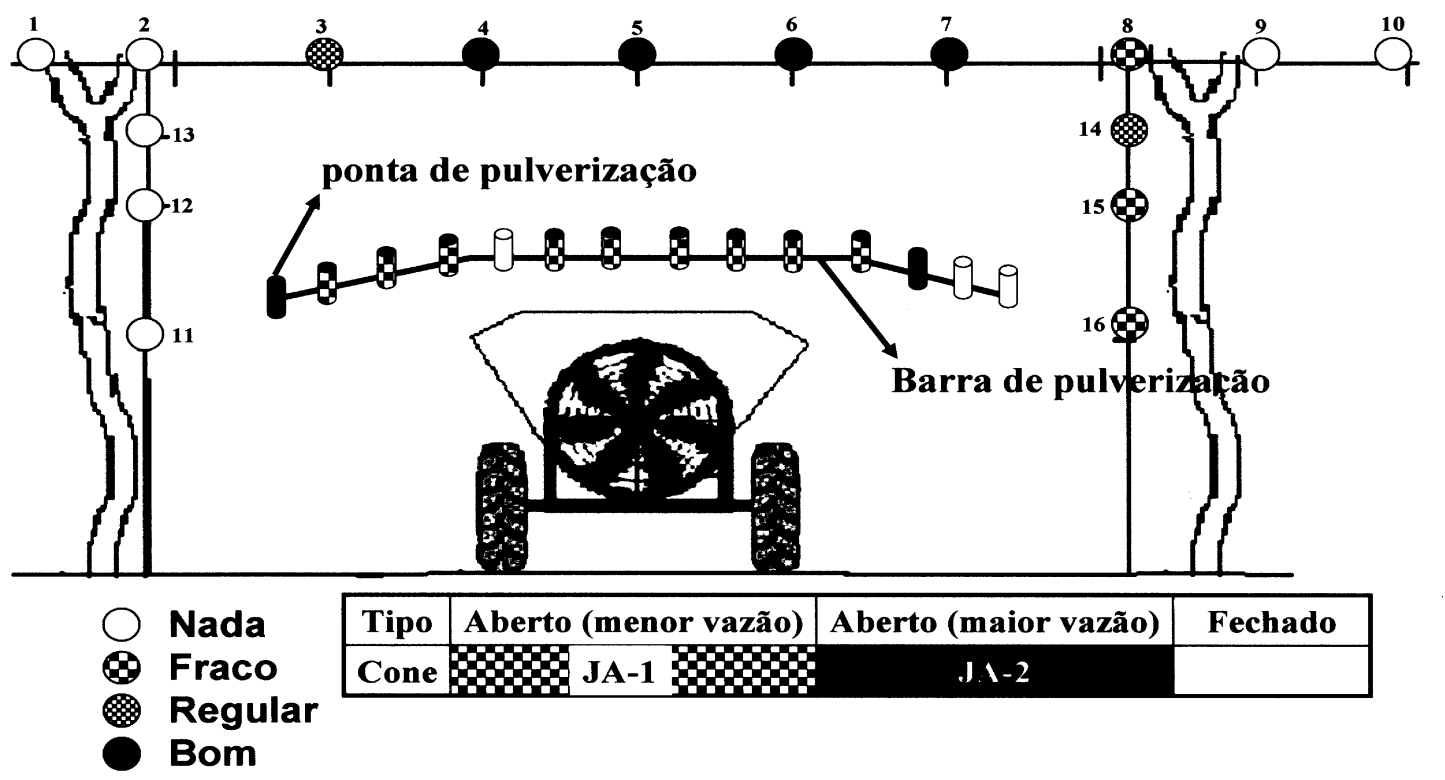

B - Configuração de pontas de pulverização considerada adequada para aplicação de agrotóxicos na videira com pontas de jato cônico JA-1 e JA-2, e as respectivas coberturas dos pontos de amostragem.

Figura 2 - Configurações de pontas de pulverização. 


\section{AGRADECIMENTOS}

Ao Conselho Nacional de Desenvolvimento Científico e Tecnológico (CNPq) e à Associação Norte Paranaense de Estudos em Fruticultura-ANPEF-pelo apoio concedido.

\section{FONTESDEAQUISIÇÃO}

a, b, c A citação de marcas comerciais não implica na recomendação de uso por parte dos autores.

\section{REFERÊNCIAS}

ABI SAAB, O.J.G. Avaliação de um sistema de aplicação de defensivos utilizado em videiras no Município de Londrina/PR. 1996. 65f. Dissertação (Mestrado em Agronomia/ Energia na Agricultura) - Faculdade de Ciências Agronômicas, Universidade Estadual Paulista.

BLANCA, A.L. Maquinaria agrícola: constitución, funcionamiento, regulación y cuidados. 3.ed. Madrid: Ministério da Agricultura, Pesca e Alimentação, 1999. 361p.

BARCELLOS, L.C. et al. Estudo sobre a penetração de gotas de pulverização no dossel da cultura da soja [Glycine Max. (L.) Merrill]. Engenharia na Agricultura, v.6, n.2, p.81-94, 1998.

CHRISTOFOLETTI, J.C. Considerações sobre a deriva nas pulverizações agrícolas e seu controle. São Paulo: Teejet South América, 1999. 15p.

CROSS, J.V. et al. Spray deposits and losses in different sized apple trees from an axial fan orchard sprayer: 3. Effects of air volumetric flow rate. Crop Protection, v.22, p.381-394, 2003.

FURNESS, G.O.; PINCZEWSKI W.V. A comparison of the spray distribution obtained from sprayers with converging and diverging air jets with low volume air assisted spraying on citrus and grapevines. Journal of Agricultural Engineering Research, v.32, p.291-310, 1985.

GIL, E. Characterization of two different conceptions of pneumatic sprayer in vineyard applications. Warwick: AgrEng, 2000. 8p. (Paper n.00-PM-033).

GIL, E. et al. Design and verification of a moving equipment for orchard and vineyard sprayer calibration. Madrid: AgEng, 1996. 8p. (Paper n96A-141).

GIL, E. et al. Improvement of the pesticide applications in vineyard. Relationship between methodology of application and quality parameters. Oslo: AgEng, 1998. 8p. (Paper n.98-A-015).

GOHLICH, H. Deposition and penetration of sprays. In SYMPOSIUM ON APPLICATION AND BIOLOGY, 1985. Proceedings... British Crop Protection Council, 1985. Monogram n.28, p.173-182
HOLOWNICKI, R. et al. Automatic self adjusting air-jet sprayer concept for fruit trees. Warwick: AgEng, 2000. 10p. (Paper n.00-PM-053).

HOLOWNICKI, R. et al. The effect of air jet velocity on spray deposit in an apple orchard. Aspects of Applied Biology, v.66, p.277-283, 2002.

KAUL, K. et al. Mechanisms of distribution of plant protection products sprayed in orchards. Nachrichtenblatt des Deutschen Pflanzenschutzdienstes, v.54, n.5, p.110-17, 2002.

MATTHEWS, G.A. A review of the use of air in atomization of sprays, dispersion of droplets down wind and collection on crop foliage. Aspects of Applied Biology, v.57, p.21-27, 2000

NOGUEIRA., H.C. Avalição da uniformidade de deposição e perdas de calda na utilização de um pulverizador desenvolvido para aplicação de herbicidas em ferrovias. 1996. 72f. Dissertação (Mestrado em Agronomia/ Energia na Agricultura) - Faculdade de Ciências Agronômicas, Universidade Estadual Paulista.

PERGHER, G. et al. The effect of spray application rate and airflow rate on foliar deposition in a hedgerow vineyard. Journal of Agricultural Engineering Research, v.61, p.205-216, 1995.

PERGHER, G. et al. Foliar deposition and pesticide losses from three air-assisted sprayers in a hedgerow vineyard. Crop Protection, Oxford, v.16, n.1, p.25-33, 1997.

PEZZI, F.; RONDELLI, V. The performance of an air-assisted sprayer operating in vines. Journal of Agricultural Engineering Research, v.76, p.331-340, 2000.

RAMOS, H.H. Pulverização-qualidade na aplicação. Cultivar máquinas, 2004. V.3, n.27, 10p. (Caderno técnico).

RANDALL, J.M. The relationships between air volume and pressure on spray distribution in fruit trees. Journal of Agricultural Engineering Research, v.16, p.1-31, 1971.

SATOW, T. et al. Influence of droplet size of spray on drift characteristics. Research Bulletin of Obihiro University, v.18, p.97-104, 1993.

SILVEIRA, G.M. Máquinas para plantio e condução de culturas. Viçosa: Aprenda Fácil, 2001. 334p. (Série Mecanização, v.3).

STEDEN, C. Untersuchungen zum einflub der tropfengröbe auf die belagsbildung und die biologische wirksamkeit gegen Oidium tuckeri Berk. an reben. 1992. 118f. Inaugural Dissertation (zur Erlangung des Doktorgrades Justus-Liebig-Universität Gieben) - Justus-LiebigUniversität Gieben, Gieben.

VEREECKE, E. et al. The air distribution generated by air-assisted sprayers. Warwick: AgEng, 2000. (Paper n.00PM-071).

VIEIRA, S.; HOFFMANN, R. Estatística experimental. São Paulo: Atlas, 1989. 66p. 